\title{
INDIVIDUALISMO NA ÉTICA AMBIENTAL BIOCÊNTRICA ${ }^{1}$
}

\author{
RAFAEL MENDONÇA ${ }^{2}$ \\ Programa de Doutorado Interdisciplinar em Ciências Humanas, UFSC
}

\begin{abstract}
This article analyses the arguments, concepts, proposals and conceptions of the Biocentric Environmental Ethic, developed in the book Respect for Nature from Paul Warren Taylor. In six brief movements, this article analyses: [i] its conception of genuine environmental ethic; [ii] its Belief System; [iii] the Attitude of Respect for Nature; [iv] the Ethic System; [v] the case of Moral Dilemmas and the Priority Principles; and, finally, [vi] the appliance limit established by Taylor for his Ethic. Key words: Environmental ethics, biocentrism, biocentric individualism, Paul Warren Taylor.
\end{abstract}

\section{Resumo}

Este artigo analisa os argumentos, conceitos, propostas e concepção da Ética Ambiental Biocêntrica, desenvolvida no livro, Respect for Nature de Paul W. Taylor. Em seis breves movimentos, são analisados nesse artigo: [i] a concepção de ética ambiental genuína; [ii] seu sistema de crenças; [iii] a atitude de respeito pela natureza; [iv] o sistema ético; [v] a questão dos dilemas morais e princípios de prioridade; e, finalmente, [vi] o limite de aplicação da Ética estabelecida por Taylor.

Palavras-chave: Ética Ambiental, biocentrismo, individualismo biocêntrico, Paul Warren Taylor.

\section{Introdução}

Respect for Nature 3 , livro de Paul W. Taylor, marcou definitivamente o futuro da ética ambiental, com a proposta de uma ética ambiental biocêntrica, na qual desenvolve um sistema de crenças para respeitar o bem-próprio das coisas vivas em sua singularidade. A teoria de Taylor foi denominada, por outros eticistas, de individualismo biocêntrico. Essa denominação se dá porque o autor se afasta de concepções holistas, as que considerem moralmente respeitáveis as espécies, em detrimento, muitas vezes, dos indivíduos que as constituem.

$\mathrm{Na}$ ética de Taylor o valor se encontra em cada singularidade e não em uma categoria abstrata. Dessa maneira, nunca o agente moral poderia sacrificar o bem inerente de um indivíduo em nome do suposto bem inerente de sua espécie; por exemplo, matar um humano em nome da melhora das condições de vida da humanidade; ou, matar um animal ou um conjunto de animais para restituir o equilíbrio de um ecossistema. Para Taylor, o bem próprio se encontra no corpo e mente de cada indivíduo, não em classes ou categorias (espécies) criadas pelos humanos. Cada ente vivo é levado em consideração dentro de sua singularidade.

Em seis breves movimentos, são analisados nesse artigo: [i] a concepção de ética ambiental 
genuína; [ii] o sistema de crenças da ética ambiental biocêntrica; [iii] a atitude de respeito pela natureza; [iv] o sistema ético: regras de conduta, padrões de caráter e virtudes; [v] a questão dos dilemas morais e princípios de prioridade; e, finalmente, [vi] o limite de aplicação da Ética estabelecida por Taylor.

\section{A ética ambiental biocêntrica de Taylor}

Taylor publica em 1986 a obra, Respect for Nature, na qual elenca fundamentos racionais para uma ética ambiental genuína, organizada em um sistema de princípios morais os quais deveriam ser seguidos no relacionamento humano com ecossistemas naturais e suas comunidades de vida silvestres. ${ }^{4}$ Para ele,

Os princípios éticos que governam essas relações determinam nossos deveres, obrigações e responsabilidades com o ambiente natural da Terra e todos os animais e plantas que a habitam. Eu uso o termo 'mundo natural' para referir o conjunto de ecossistemas naturais em nosso planeta, junto com as populações de animais e plantas constituintes da comunidade biótica desses ecossistemas. ${ }^{5}$

Quando Taylor se refere à ética ambiental genuína, ele quer dizer que as demais éticas, antropocêntricas, ou senciocêntricas, não cumprem com o papel de terem seus princípios aplicados de forma universal, pois são éticas, no dizer de Sônia Felipe, ou dicotomizadas (dividindo um conjunto de princípios e regras éticas para as relações com humanos e outro para com animais) ou mesmo tricotomizadas (dividindo em uma ética para humanos, outra para animais e outra para plantas). Taylor pretende desenvolver uma ética que, ao ser seguida pelo agente moral, seja aplicável a quaisquer pacientes morais de suas ações, independentemente da aparência desses.

Uma divisão conceitual importante na teoria de Taylor se refere ao agente moral e ao paciente moral, assim definidos por ele:

Um agente moral [...] é qualquer ser possuidor daquelas capacidades que lhe
permitem agir moral ou imoralmente, que pode ter deveres e responsabilidades.
Dessas capacidades, as mais importantes são [1] a habilidade de formar julgamentos
sobre o certo e o errado; [2] a habilidade de deliberação moral, isto é, de considerar
e pesar razões morais a favor ou contra formas de conduta abertas à escolha; [3]
a habilidade de tomar decisões com base naquelas razões; [4] a habilidade para
exercer a ação necessária e força de vontade para manter aquelas decisões; e [5]
a capacidade de responder a outros por falhar no cumprimento daquelas. [...] Nós
podemos definir um paciente moral como qualquer ser que pode ser tratado de
forma correta ou errada; em relação ao qual os agentes morais podem ter deveres
e responsabilidades. Deve ser possível para estes seres terem suas condições de 
existência tornadas melhor, ou pior, pelas ações dos agentes. [...] Pacientes morais devem ser entidades que possam receber benefícios ou sofrer malefícios. ${ }^{6}$

Nessa perspectiva, entram na considerabilidade ética todos os entes vivos, além dos animais e dos humanos, que podem receber benefícios ou sofrer malefícios

O ponto de referência proposto na ética é o do paciente moral, uma ética para limitar o poder dos agentes morais. ${ }^{7}$ Afirma Taylor:

Talvez o fato eticamente de maior significância sobre os pacientes morais é que sempre é possível para um agente moral colocar-se na perspectiva do paciente moral e fazer julgamentos do ponto de vista daquele, sobre como deve ser tratado. O padrão implícito nesses julgamentos é a ampliação ou preservação do bem-estar do paciente, não daquele que está julgando. ${ }^{8}$

O autor escreve sua ética tomando por referência a ética humana. Assim, por analogia, estabelece condições formais e materiais para a existência da ética. Todos os princípios e regras devem satisfazer essas condições para serem incluídos no sistema ético normativo, considerado válido. ${ }^{9}$ As cinco condições formais da ética humana se mantêm. ${ }^{10}$ A norma ética deve:

(a) ser geral na forma; ${ }^{11}$

(b) ser considerada universalmente aplicável para todos os agentes morais, ${ }^{12}$

(c) pretender ser aplicada imparcialmente, ${ }^{13}$

(d) ser advogada como princípio normativo adotado por todos; ${ }^{14} \mathrm{e}$

(e) ser tomada como acima de todas as normas não-morais. ${ }^{15}$

Ao preencher essas condições formais, a norma é considerada válida moralmente no sentido formal. Ela necessita, em seguida, preencher as condições materiais. Na ética de Taylor, a condição material corresponde à atitude de respeito pelas pessoas.

Subsumida a essa condição, a estrutura da ética ambiental será delineada em três componentes principais:

1. ${ }^{\circ}$ A aceitação de um sistema de crenças com o qual o agente moral considere os demais;

2. ${ }^{\circ}$ A atitude de respeito pelas pessoas em consideração;

3. ${ }^{\circ}$ Um sistema de regras e padrões considerados válidos (atendendo às condições formais de (a) a (e) acima listadas. 


\section{O sistema de crenças da perspectiva biocêntrica}

Para Taylor, o sistema de crenças institui a visão de mundo e o estatuto sobre o qual deve estar fundado o relacionamento dos agentes morais com as coisas vivas do ambiente natural. $\mathrm{O}$ autor aponta a condição humana paradigmática, quando afirma: "O que o mundo natural tem de significante moral para nós, depende da maneira que olhamos para todo o sistema da natureza e nosso papel nele." 16

As crenças que constituem o corpo da perspectiva biocêntrica estão dispostas em número de quatro:

(a) Humanos são membros da comunidade de vida da terra no mesmo sentido e nos mesmos termos nos o são as outras coisas vivas dessa comunidade;

(b) A espécie humana e as outras espécies integram um sistema vivo de interdependência em que a sobrevivência de cada coisa viva e suas chances de viver bem, ou mal, são determinadas não só pela condição física do meio ambiente, mas também pelas relações com as outras coisas vivas;

(c) Todos os organismos vivos são centros teleológicos de vida, no sentido de que cada um é um indivíduo singular buscando e encontrando seu bem-próprio, à sua maneira especifica; e, por fim,

(d) Os humanos não são inerentemente superiores às outras coisas vivas. ${ }^{17}$

No entender de Taylor, "Aceitar as quatro crenças significa ter uma visão coerente do mundo natural e do lugar dos humanos nele." ${ }^{18}$ Cada uma dessas crenças distingue o sistema de crenças da ética ambiental biocêntrica, da antropocêntrica. As crenças que sustentam a ética biocêntrica são testadas e aprovadas com fundamento em quatro critérios de qualidade:

(a) serem abrangentes e completas;

(b) estarem ordenadas de forma sistemática, coerente e internamente consistentes;

(c) serem livres de obscuridade, confusão conceitual e vagueza semântica;

(d) serem consistentes com todas as verdades empíricas. ${ }^{19}$

\section{A atitude de respeito pela natureza}

A ética de Taylor se propõe a ser uma alternativa à concepção ética antropocêntrica do 
ambiente. Para o autor,

\begin{abstract}
Uma teoria da ética ambiental centrada no humano postula que nossos deveres morais de respeito ao mundo natural são completamente derivados da obrigação que devemos a outro ser humano. É porque deveríamos respeitar os direitos humanos de cada um, ou deveríamos proteger e promover o bem-estar dos humanos, que precisamos colocar certas restrições em nosso tratamento ao ambiente natural da Terra e aos habitantes não-humanos." 20
\end{abstract}

Ao contrário da perspectiva antropocêntrica, o biocentrismo atribui bem inerente à toda coisa viva silvestre, por ser possuidora de bem-próprio. Dessa maneira,

\begin{abstract}
Um dos princípios fundamentais da teoria da ética ambiental biocêntrica é que todos os animais, não importando quão diferentes sejam dos humanos, são seres que têm um bem-próprio. Um segundo princípio, igualmente fundamental, afirma serem todas as plantas, semelhantemente aos animais, possuidoras de um bem-próprio. ${ }^{21}$
\end{abstract}

Nesse ponto, duas categorias importantes são apresentadas aos agentes morais, para fundar sua atitude de respeito pela natureza, a saber:

[i] bem-próprio (good of its own): afirmar que uma entidade possui bem-próprio significa reconhecer que ela tem interesses, no sentido de ter fins e encontrar meios para alcançar esses fins, ${ }^{22}$ nela mesma; e,

[ii] bem inerente (inherent worth): da afirmação de que uma entidade tem um bem inerente, advém dois julgamentos morais:

Primeiro: o reconhecimento do paciente moral dotado de um bem-próprio; e,

Segundo: que todos os agentes morais têm o dever prima facie de promover e preservar o bem-próprio do paciente moral, por ter um fim em si mesmo. ${ }^{23}$

\title{
O sistema ético: regras de conduta, padrões de caráter e virtudes
}

Constituem o sistema de princípios, ordenados para orientar os agentes morais na sua atitude de respeito pela natureza, as (i) regras de conduta, (ii) os padrões de bom caráter e (iii) os tipos de virtudes (associadas aos dois primeiros).

As quatro regras de conduta fundamentais da ética biocêntrica são: 
(a) Não-Maleficência: dever de não causar dano a nenhuma entidade do meio natural possuidora de bem-próprio, incluindo o dever de não matar um organismo e de não destruir a população de uma espécie ou uma comunidade biótica. ${ }^{24}$

(b) Não-Interferência: dever de não impor restrições à liberdade de organismos individuais e ter uma política de distanciamento (hands off policy) dos ecossistemas, comunidades bióticas e organismos individuais..$^{25}$

(c) Fidelidade: dever de não trair a confiança de um animal silvestre no ambiente em que vive. Exemplos de quebra na fidelidade com os animais em estado natural: caça, armadilhas, pesca etc. Tais ações implicam a quebra dos dois primeiros princípios. ${ }^{26}$

(d) Justiça Restitutiva: dever de restaurar a eqüidade entre o agente e o paciente moral, quando este for prejudicado por aquele. Essa regra somente se aplica quando o agente moral quebra uma das três regras morais anteriores. ${ }^{27}$

A atitude de respeito pela natureza, diz Taylor, será expressa no caráter quando o agente tiver desenvolvido de forma segura, prática e permanente, disposições que lhe capacitem deliberar e agir eficazmente seguindo as quatro regras de dever: não-maleficência, não-interferência, fidelidade e justiça restitutiva. As disposições são virtudes, ou traços de bom caráter, os quais tornam possível um agente moral agir em conformidade com as regras e, assim fazendo, expressar em sua conduta a atitude de respeito pela natureza. ${ }^{28}$

Taylor sugere a divisão das virtudes, em dois tipos: as virtudes gerais e as virtudes especiais. As oito virtudes gerais garantidoras da força moral do agente são: 1 . senso de realidade; 2. integridade; 3. paciência; 4. coragem; 5. temperança (autocontrole); 6. imparcialidade; 7. perseverança; e, 8. firmeza de propósito.

As quatro virtudes gerais garantidoras da empatia moral são: 1. benevolência; 2. compaixão; 3. simpatia; e, 4. caridade.

As seis virtudes especiais são: 1. altruísmo (relacionada à regra da não-maleficência); 2. respeito aos limites (relacionada à regra da não-interferência); 3. imparcialidade (relacionada à regra da não-interferência); 4. confiabilidade (relacionada à regra da fidelidade); 5. justiça (relacionada à regra da justiça restitutiva); e, 6. eqüidade (relacionada à regra da justiça restitutiva).

Essas virtudes constituem um bom caráter e o agente moral precisa desenvolvê-las para dar conta de seguir as regras da ética do respeito pela natureza. ${ }^{29}$

\section{Dilemas morais e princípios de prioridade}

No último capítulo de sua obra, Taylor apresenta princípios de prioridade para resolver dilemas morais surgidos quando valores e direitos humanos conflitam com o bem de não-humanos. 
Conflitos de interesses entre humanos e não-humanos não podem ser evitados. Os humanos competem com animais e plantas quando usam o meio ambiente natural e também no momento de consumir algum ente vivo para sobreviver. Dessa maneira, o dilema ocorre quando, ao se adotar a atitude de respeito pela natureza, concorrem dois interesses básicos de entidades vivas, ambas com bem inerente.

Para a resolução dos conflitos, com justiça, Taylor propõe cinco princípios de prioridade, quais sejam:

(1) O Princípio da autodefesa: permite aos agentes morais se protegerem contra organismos danosos ou perigosos, destruindo-os, caso necessário. ${ }^{30}$

(2) O Princípio da proporcionalidade: em um conflito entre valores humanos e o bem de animais e plantas silvestres, maior peso deve ser dado aos interesses básicos do que aos não-básicos, não importando as espécies em competição. Esse princípio proíbe a sobreposição de interesses básicos, por interesses não-básicos, mesmo quando os interesses não-básicos forem de humanos e os básicos de animais e plantas; ${ }^{31}$

(3) O Princípio do mal-menor: aplica-se a situações nas quais, (i) interesses básicos de animais e plantas estão inevitavelmente em competição com interesses não-básicos humanos; (ii) interesses humanos em questão não são intrinsecamente incompatíveis com o respeito pela natureza; (iii) ações necessárias para satisfazer aqueles interesses, contudo, são prejudiciais aos interesses básicos de animais e plantas; e (iv) interesses humanos envolvidos são tão importantes que pessoas racionais e bem informadas, com genuíno respeito pela natureza, são forçadas a aceitar a busca daqueles interesses, mesmo quando eles implicam em conseqüências indesejáveis à vida silvestre; ${ }^{32}$

(4) O Princípio da justiça distributiva: critério para a justa distribuição dos bens garantidores de satisfação dos interesses de todas as partes em conflito, quando todos esses interesses são básicos, portanto, de igual importância para os envolvidos. Por serem de igual importância, eles têm o mesmo peso moral. A equanimidade no peso, preservado na decisão que soluciona o conflito é o que garante justiça para todos; ${ }^{33}$

(5) O Princípio da justiça restitutiva: aplicável sempre após o princípio do mal-menor e da justiça distributiva. Se forem causados danos a não-humanos por agentes morais, alguma forma de reparação ou compensação deve ser feita, para que as ações dos agentes morais sejam completamente consistentes com a atitude de respeito pela natureza. ${ }^{34}$

\section{O limite de aplicação da ética estabelecida por Taylor}

Finalmente, cabe observar a justificativa da delimitação à aplicabilidade da estrutura teórica desenvolvida por Taylor, restrita a ecossistemas naturais e suas comunidades de vida silvestres. ${ }^{35}$ 
No sistema de crenças da perspectiva biocêntrica, todas as entidades vivas possuidoras de bem-próprio são passíveis de reconhecimento de bem inerente, mas a característica marcante da teoria está na limitação exata dos pacientes morais aos quais ela se aplica, qual seja: somente coisas vivas em estado de não manejo humano. Dito de outra forma, seres e coisas vivas em comunidades de vida nas quais os fatores determinantes da estrutura de suas relações se mantêm sem qualquer intervenção humana.$^{36}$ Por essa delimitação expressa, o sistema teórico não se aplica aos entes vivos, ecossistemas ou comunidades bióticas já manejadas pelos humanos. Essa delimitação é alvo de diversas críticas formuladas por pensadores posteriores.

Mas o que levaria Taylor a restringir sua teoria aos entes vivos que nunca tenham sofrido interferência dos humanos, deixando de lado justamente os entes que mais sofrem danos dos agentes morais, por exemplo, animais fabricados para suprir a indústria da carne, leite e ovos?

A razão para a delimitação se dá por uma questão de cautela e, principalmente pela dificuldade em estabelecer uma ética ambiental genuína quando em uma sociedade especista os agentes morais criam, fabricam, regulam e exploram sistematicamente os pacientes morais, por exemplo, o caso dos animais e plantas fabricados ou domesticados nos ambientes manejados. ${ }^{37}$

Não seria possível falar em ética genuína, ou mesmo em ética ambiental biocêntrica, em Taylor, quando os agentes morais manipulam as demais formas de vida, destituindo-as do que seria o bem próprio, e subtraindo-lhes a liberdade para buscá-lo a sua própria maneira. Por conta disso, em sua obra de 1986, Respect for Nature, Taylor se restringe a falar dos entes silvestres, aqueles nos quais o bem inerente (inherent worth), e a mente específica não foi destruída pelo manejo humano. A consideração igualitária e de respeito aos entes vivos com bem inerente não é compatível com o valor instrumental tradicional atribuído aos entes vivos pelos empreendimentos da biocultura ${ }^{38}$. 


\section{Notas}

${ }^{1}$ Artigo apresentado como trabalho final para o Seminário de Ética Prática do curso de Pós-Graduação em Filosofia, UFSC, orientado pela Dr. ${ }^{\text {a }}$ Sônia T. Felipe, no segundo semestre de 2007. Uma versão preliminar deste texto foi apresentada no $2^{\circ}$ Congresso Vegetariano Brasileiro, realizado em Setembro de 2008, em Belo Horizonte.

${ }^{2}$ Doutorando do Programa de Pós-Graduação Interdisciplinar em Ciências Humanas da Universidade Federal de Santa Catarina; Mestre em Ciência Jurídica, na linha de Hermenêutica e Principiologia Constitucional, pela Universidade do Vale do Itajaí; Bacharel em Ciências Jurídicas pela Universidade da Região de Joinville.

${ }^{3}$ TAYLOR, Paul W. Respect for Nature: A Theory of Environmental Ethics. 2. impress with corrections. New Jersey, Princeton: Princeton University Press, 1987. 330 p.

${ }^{4}$ Idem, Ibid., p. 9. "A idéia de ecossistema natural como deve ser entendida nesse livro significa qualquer conjunto de coisas vivas ecologicamente interrelacionadas que, sem a intrusão ou controle humano, mantém sua existência como população-espécie ao longo do tempo. Cada população ocupando seu próprio espaço natural e cada uma adaptada pelos processos evolutivos de variações genéticas e seleção natural.” Ibid., p. 3.

${ }^{5}$ Ibid.

${ }^{6}$ Ibid., p. 15-17.

7 Similar à "perspectiva do universo" de Henry Sidgwick em The Methods of Ethics (1874) ou a do "observador imparcial" de David Hume.

8 TAYLOR, Paul W. Respect for Nature, p. 17.

9 “Por 'válido' quero dizer que as regras e padrões do sistema estão verdadeiramente vinculando (impõem requisitos morais para) todos os agentes morais." Ibid., p. 25.

${ }^{10}$ Ibid., p. 26-27.

11 “Uma regra ou padrão é geral na forma, quando não contém nenhuma referência a pessoas particulares ou ações, somente mencionando tipos de coisas em termos de suas propriedades. Portanto, uma regra moral válida nunca declara que um indivíduo ou grupo específico deve realizar certa ação em certo momento e lugar.” Ibid., p. 27.

12 "Uma regra moral ou padrão deve ser um princípio normativo possível de aplicação universal por todos os seres os quais são agentes morais, e deve ser concebida para ser universalmente aplicável por aqueles que a subscrevem como uma norma moral validamente vinculante.” Ibid., p. 28.

13 "Elas devem pretender ser aplicadas imparcialmente, por questões de princípio. Elas servem como 'imperativos categóricos' nos termos de Kant. Se uma regra ou padrão é uma norma moral válida, ela deve ser subscrita como princípio a ser seguido por qualquer agente moral, independentemente de seus fins particulares ou interesses." Ibid., p. 29.

14 “A quarta condição adiciona algo às três primeiras [...], ao estipular que uma regra moral ou padrão é válida somente se aqueles que a adotam como sua própria referência normativa tiverem uma atitude de aprovação sobre sua adoção por todos os outros [agentes morais - estabelecendo um senso público de justiça. Deve ser uma norma publicamente adotável]." Ibid., p. 31.

15 “A última condição formal é que a regra moral ou padrão somente pode ser válida se aqueles que a aceitam derem a ela um peso supremo e advogarem que todos os outros dêem a ela esse peso supremo.” Ibid., p. 32.

${ }^{16}$ Ibid., p. 99.

${ }^{17}$ Ibid., p. 99-100.

${ }^{18}$ Ibid., p. 100.

${ }^{19}$ Ibid., p. 158-159.

${ }^{20}$ Ibid., p. 11.

${ }^{21}$ Ibid., p. 66.

22 "Promover o bem-próprio é ao mesmo tempo encontrar um estado de bem-estar ainda não constituído na sua existência para a condução de seu bem, ou extirpar uma condição na sua existência que reduza seu bem. Proteger o bem-próprio pode ser feito de diversas formas: evitando lhe causar dano (ou seja, abstendo-se de fazer algo contrário ao seu bem); prevenindo a perda de algo necessário à preservação de seu bem, e lhe mantendo a salvo do perigo, evitando danos que poderiam lhe advir. Todas essas formas de promoção e proteção do bem-próprio são, por definição, benéficas para a entidade." Ibid., p. 62.

${ }^{23}$ Ibid., p. 75.

${ }^{24}$ Ibid., p. 172-173.

25 Ibid., p. 173-179.

${ }^{26}$ Ibid., p. 179-180.

${ }^{27}$ Ibid., p. 186.

${ }^{28}$ Ibid., p. 172-173. 
${ }^{29}$ Ibid., p. 198-218.

${ }^{30}$ Ibid., p. 264.

${ }^{31}$ Ibid., p. 278

${ }^{32}$ Ibid., p. 280.

${ }^{33}$ Ibid., p. 292.

${ }^{34}$ Ibid., p. 304.

${ }^{35}$ Ibid., p. 9. "A idéia de ecossistema natural como deve ser entendida nesse livro significa qualquer conjunto de coisas vivas ecologicamente interrelacionadas que, sem a intrusão ou controle humano, mantém sua existência como população-espécie ao longo do tempo. Cada população ocupando seu próprio espaço natural e cada um adaptado pelos processos evolutivos de variações genéticas e seleção natural.” Ibid., p. 3.

${ }^{36}$ Ibid., p. 3-4.

${ }^{37}$ Ibid., p. 53-58.

38 "A biocultura é um conjunto de instituições sociais e práticas. É um aspecto de qualquer cultura humana na qual humanos criam e regulam as coisas vivas em um ambiente e sistematicamente lhes exploram para benefício humano." Ibid., p. 53. 


\section{Referências bibliográficas}

TAYLOR, P, W. Respect for Nature: a theory of environmental ethics. 2. impress with corrections. New Jersey, Princeton: Princeton University Press, 1987. 330 p. 